\title{
Meta-Analysis on Relations between E-Learning Research Trends and Effectiveness of Learning
}

\author{
Jeong-Kyoum $\mathrm{Kim}^{1}$ and Deuk-Joon $\mathrm{Kim}^{2 *}$ \\ ${ }^{1,2}$ Departmnet of Education, College of Education, Chungnam National University, \\ 99 Daehangno,Yuseong-gu, Daejeon 305-764, South Korea \\ jgkim426@cnu.ac.kr,deukjoon@gmail.com
}

\begin{abstract}
This study seeks to investigate research trends on e-learning in Korea for the past 10 years and meta-analyze relations between e-learning and its effectiveness with an eye on confirming the effectiveness of e-learning. The analysis showed that there is a high correlation between changes in the society's overall interest in e-learning and the number of published papers on related subjects $(r=.672)$. Early on, researches focused on applicable areas for e-learning, but the focus gradually shifted towards design. In terms of research method, survey based on paper questionnaires or data analysis on research subjects showed a high percentage (49.3\%), and research areas have been found to be meaningfully related to research methods (Fisher's exact test: 42.019, $p=.012$ ). Overall effectiveness of learning through e-learning proved positive, but the mean effect size was somehow small (Mean $E S=.301$ ). When e-learning's effectiveness was studied in consideration of learners' background variables and e-learning environmental variables, the latter was found to have a greater effect.
\end{abstract}

Keywords: e-learning, Learning effect, Meta-analysis, Research Trend, Fisher's exact test

\section{Introduction}

E-learning is an education system which is created by combining digital media and education. E-learning is based on the Internet and information communication technology. As a main characteristic, if the Internet is available, a learner can study regardless of time and place. Other than that, many advantages of e-learning have been mentioned from various aspects. Following this trend, e-learning has now been considered as a main learning method to manage and improve knowledge and performance effectively, which is required in knowledge-based society. As its demand of e-learning by the society increases and its utilization is generalized, studies related e-learning have also been carried out actively and the study areas have been mostly concentrated on variable identification with regard to e-learning effectiveness.

The study on learning effectiveness of e-learning is largely categorized into a study on variables of characteristics of learners such as motivation, expectation and self-directed learning ability, a study on variables of supporting system such as assistance of organization and colleagues, and a study on variables of e-learning systems such as design and quality of contents and sufficient media provided. These previous studies claimed that variables of elearning effectiveness such as learner's characteristics, supporting systems and e-learning system were positively related to learning effect. For example, the higher a learner has self-

* Corresponding Author 
directed learning ability, or the better the supporting system or e-learning system is , the more learners have satisfaction and the higher learners have learning performance. However, on the contrary, there were also many studies that said differently about it. That is, characteristics of learners (Jung and Kim (2006) [1]; Hwang and Choi (2006) [2], supporting systems (Hwang and Choi (2006)) [2] and e-learning system environment (Jung and Kim (2006); Park and Kim (2008)) [1, 3] had no correlation with the e-learning effectiveness.

These inconsistent results of the studies caused much confusion in effective practice and applications of e-learning. As an example, while Korea introduces digital text books, many controversies about effectiveness of the digital textbooks have arisen. Therefore, it is now required to identify the learning effect of e-learning, which has completed the enforcement step in the Three-step Measures for Comprehensive Education Information Advancement and in preparation of new education innovation through smart education has just started. The study trend and the analysis of the study results have been centered on literature reviews, but they failed to provide objective data, and it was the limitation of their studies.

In this study, to guarantee reliability of the learning effect of e-learning, specific journals related to education engineering were selected first to analyze the e-learning-related study trend and variables with regard to the learning effect of e-learning were derived. Further, quantity of overall learning effect, quantity of learning effect under variables of learner's characteristics, and quantity of learning effect under variables of e-learning environment were calculated and their results were presented. Accordingly, our study can present empirical evidence that electronic media-utilized education is essentially required in a school environment as well as to provide a foundation on which e-learning-related study can be further progressed.

\section{Literature Review}

\subsection{Study on Controversy of e-learning Effectiveness}

2.1.1. Characteristics of a Learner: For the variables of characteristics of a learner, which are related to e-learning effectiveness, learning style of a learner, learning attitude, learning motivation, learner's ability and background were determined as the main variables.

Regarding the variables of a learning style, Baek et al., (2000) [4] presented that in case of the field independence learner, a fidelity level did not affect learning achievement although it was much more effective for field dependence learners to lower a fidelity level, which claimed that a learning style can influence learning achievement. In the meantime, Wang et al., (2003) [5] mentioned that learners who had a field independent cognitive style had higher mathematics and spatial perception than learners who had a field dependent cognitive style, which also claimed that a learning style can influence learning achievement.

As for a study on learning attitude, Jung et al., (2002) [6] found that positive attitude toward learning can affect education effect significantly while Kang (2002) [7] identified that satisfaction level of virtual class showed significant difference depending on attitude shown in virtual class such as sub-factors of preference, fear, and usefulness. In addition, Kwon (2001) [8] found that learning achievement was different by a level of self-directed learning attitude of a learner.

Finally, regarding a study on learning motivation, Kang (2003) [9] said that achievement motivation can influence learning achievement. Moreover, many other studies of Ryan \& Connell(1989) [10], Csilszentmihalyi, Rathunde, \& Whlen(1993) [11], Fortier, Vallerand, \& Guary(1995) [12], Guay \& Vallerand(1997) [13], and Ryan \& Deci(2000) [14] in oversea studies and Go and Kim (2010) [15], Kim (2010) [16], Lee. S (2010) [17], Lee. J (2010) [18], 
Jo and Kwon (2007) [19], Jo and Lee (2010) [20], and Ju (2011) [21] performed in Korea also mentioned that learning achievement can be different by the motivation level of a learner.

Such many studies published study results that learner's characteristics had effect on elearning effectiveness. On the other hand, Jeong and Kim (2006) [1] claimed that learner's characteristics such as self-efficacy, learning ability and expectation value did not affect the learning effect while Hwang and Choi (2006) [2] mentioned that learner's characteristics such as class experience did not affect the learning effect.

2.1.2. Supporting System: As for the main variables of a supporting system with regard to elearning effectiveness, supporting from colleagues, compensation for achievement, and organization culture were studied.

Noe (1986) [22], Baldwin \& Ford (1988) [23], and Tracey et al., (2001) [24] said that supporting environment of an organization such as awareness of an environment, supporting from senior colleagues and organization environment, and supporting systems affected the learning effect while Kim and Gwak (2004) [25] presented that supporting from the management team and compensation scheme can influence improvement of work-related performance and ability.

On the contrary, Ryu and Kim (2005) [26] said that learning assistance such as material supply, feedback and learning activity facilitation did not affect a satisfaction level between upper and lower groups while Lee, Hong and Son (2007) [27] published a study result that there was no difference of learning achievement between positive feedback, negative feedback, and voluntary feedback groups.

2.1.3. e-learning System: As for the variables of the e-learning system environment with regard to e-learning effectiveness, system reliability, contents quality, sufficient media, and user interface were studied as main variables. Kim, Han and Lee (2003) [28] said that validity of the contents details and clarification of contents can affect the learning effect of web-based remote education while Daft \& Lengel (1986) [29], Webster \& Hackley (1997) [30], Freeman (1997) [31], and Wang (2003) [32] claimed that system environments such as system reliability, contents quality, sufficient media and user interface can influence the learning effect.

On the other hand, Jeong and Kim (2006) [1] presented that system quality and sufficient media did not affect the learning effect while Park and Kim (2008) [3] found that system environment such as information presentation color did not affect the learning effect.

\subsection{Meaning of Meta-analysis}

Through the reviews on the previous studies on e-learning effectiveness, there were many contradictory claims with regard to learning effectiveness of e-learning one another, which supported or backed the claims by empirical study results. Therefore, it is required to derive strong conclusions, which are more reliable and objective, by integrating the previous study results in order to overcome the limitation of one-sided studies. Glass(1976) [33] explained the meta-analysis technique while mentioning the characteristics of the meta-analysis as follows: first, meta-analysis is quantitative. That is, it is not enumeration of simple data but uses numerical and statistical method to classify a number of study results succinctly and extract some significant meaning from numerous pieces of information which is difficult to systemize. Therefore, meta-analysis uses summary statistic, instead of using raw data as it is in a process of integration. Secondly, meta-analysis converges all the different studies to derive overall conclusions for calculation of so called the effect size. Therefore, a number of study results are not excluded from the analysis targets even if their results are contradictory 
one another or not satisfactory to meet the expected results. Even though a study result is different individually from one another, it will be analysis target to derive an overall conclusion. Therefore, individual studies are not determined whether they are included or not in the study analysis by the researcher's subjective judgment. Third, general conclusions are derived from meta-analysis. When a study result in a specific area was made, it is assumed that if we want to find a general conclusion in a case where contradictory direction or different effect size, generalization can be done if we neglect a little difference existed in fragmented study results although some study results produced positive effects while other study results generated negative effects. Therefore, meta-analysis can be defined as an effort of finding a function that can satisfy two conditions, one is generalization and the other is practical brevity, at the same time.

\section{Research Subjects and Methods}

350 papers published from 2002 to March 2013 on "Korean Association For Educational Information and Media" registered with the National Research Foundation of Korea have been selected for this study. In order to study e-learning research trends, we sorted out papers that contained such words as ‘이러닝', ‘e-러닝' or 'e-learning' in their titles and key-words. These shortlisted papers were then analyzed for trends in research areas and methods. The categorization of research areas has been benchmarked from " the research area categorization standard" used in Chung, Hyun-mi and Yang, Yong-chil's research[34], which was conducted based on 'the research areas of education engineering' defined in 1994 by the Association for Educational Communications and Technology (AECT)[35], but was adapted for this study. Research methods have been categorized based on Driscoll's [36] categorization and the developmental research by Richey and Nelson [37]. Research trends have been looked into by each phase of the Comprehensive Development Plans for Education Informatization.

The meta-analysis, which had been conducted to confirm the effectiveness of e-learning, calculated effect sizes based on papers on relations between e-learning and academic achievement. The program used for calculating effect sizes was the 'MS Excel Effect Size Computation Program’ developed by David Wilson [38].

\section{Data Analysis}

\subsection{E-Learning Trend by Year}

4.1.1. Changes of E-learning-related Terminology: For starters, this study looked into changes by year in the society' s level of interest in words such as ‘이러닝', 'e-러닝' and 'elearning', which had been used to select the papers for this study.

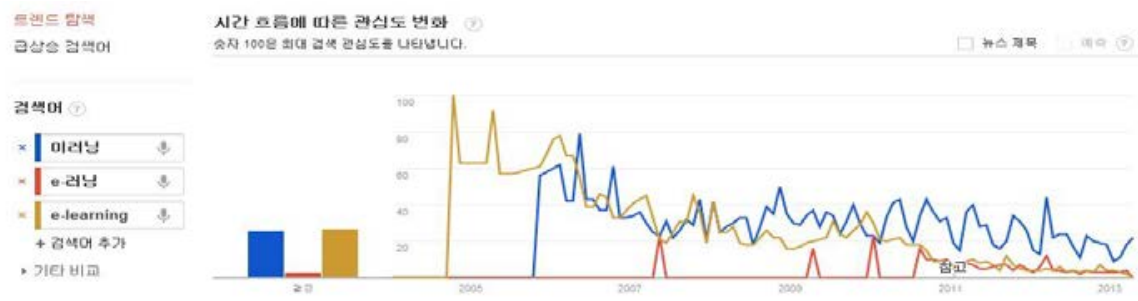

Figure 1. Changes in Interest by Time (Source: Google Trends, http://www.google.com/trends/) 
As Figure 1 shows, the use of the word 'e-learning' is predominant in early years. During the period from May 2006 to February 2010, the terms of '이러닝' and 'e-learning' are used frequently, but the former one used a slightly more often. From February 2010, however, the appearance of 'e-learning' is dominant. The use of 'e-러닝' is frequent in May 2007, April 2009 and in January 2010, but after August 2010, it shows a similar curve as that of 'elearning'. On the other hand, the level of interest in e-learning peaks in 2004 and continues to drop ever since.

4.1.2. Status of e-learning Papers by Year: The analysis on the 350 papers published from 2002 to March 2013 in the Educational Information and Media Research registered with the National Research Foundation of Korea showed that 69 of them, or 19.7\%, contained words like '이러닝', 'e-러닝' or 'e-learning' in their titles or key-words. The following is the yearly status of papers including such terms.

Table 1. Papers on e-learning

\begin{tabular}{c|c|c|c|c}
\hline Publish Year & Analysis Category & Paper on e-learning & Others & Total \\
\hline 2002 & Frequency(\%) & $3(13.6 \%)$ & $19(86.4 \%)$ & $22(100 \%)$ \\
\hline 2003 & Frequency(\%) & $0(0.0 \%)$ & $28(100.0 \%)$ & $28(100.0 \%)$ \\
\hline 2004 & Frequency(\%) & $6(18.8 \%)$ & $26(81.3 \%)$ & $32(100.0 \%)$ \\
\hline 2005 & Frequency(\%) & $8(24.2 \%)$ & $25(75.8 \%)$ & $33(100.0 \%)$ \\
\hline 2006 & Frequency(\%) & $13(27.1 \%)$ & $35(72.9 \%)$ & $48(100.0 \%)$ \\
\hline 2007 & Frequency(\%) & $11(27.5 \%)$ & $29(72.5 \%)$ & $40(100.0 \%)$ \\
\hline 2008 & Frequency(\%) & $6(17.6 \%)$ & $28(82.4 \%)$ & $34(100.0 \%)$ \\
\hline 2009 & Frequency(\%) & $6(17.1 \%)$ & $29(82.9 \%)$ & $35(100.0 \%)$ \\
\hline 2011 & Frequency(\%) & $7(26.9 \%)$ & $19(73.1 \%)$ & $26(100.0 \%)$ \\
\hline 2012 & Frequency(\%) & $4(15.4 \%)$ & $22(84.6 \%)$ & $26(100.0 \%)$ \\
\hline 2013 & Frequency(\%) & $4(20.0 \%)$ & $16(80.0 \%)$ & $20(100.0 \%)$ \\
\hline Total & Frequency(\%) & $1(16.7 \%)$ & $5(83.3 \%)$ & $6(100.0 \%)$ \\
\hline
\end{tabular}

Based on the changes in the level of interest shown in Figure 1 and the data on e-learning papers in Table 1, changes in the level of interest in the e-learning terms were looked into in relation to the status data on e-learning papers. The two showed a high correlation as Table 2 displays. 


\section{Table 2. Correlation Coefficient between Level of Interest and Number of} Papers

\begin{tabular}{l|c|c|c|c}
\hline \multirow{2}{*}{} & \multirow{2}{*}{ Mean } & Std. Deviation & \multicolumn{2}{|c}{ Correlations } \\
\cline { 3 - 5 } & & & $(1)$ & $(2)$ \\
\hline (1) Change in Interest & 17.04 & 8.326 & 1 & $.672^{*}$ \\
\hline (2) \% of e-learning Papers & $21.13 \%$ & $4.794 \%$ & 1 \\
\hline
\end{tabular}

*. Correlation is significant at the 0.05 level (2-tailed).

\subsection{Trend Analysis by Research Area}

Two researchers and four graduate students (two in the doctorate and master' s programs each) majoring in education engineering participated in the process of sorting out 350 papers and selecting 69 of them that contained words like '이러닝', 'e-러닝' and 'e-learning'. To better perform the paper sorting task, the four students were given a workshop on the categorization criteria for research areas and methods written by the researchers. After the workshop, two people were paired together to form a group each, resulting in three teams. Each team was assigned papers and asked to carry out an initial category coding on them. These teams conducted the coding independently of the others and, if their coding results did not match, the two researchers reviewed the papers in question and determined the category code. When the initial coding was done, one researcher looked through the coding results of all papers once again, through which errors made by the students were checked and corrected. For those papers which had not still been given a clear code, the other researcher carried out an independent coding on them and checked to see if their results matched. If the results still disagreed, the two researchers had a final discussion to decide on a code. Table 3 shows the analysis results.

\section{Table 3. Research Trends by Phase of the Comprehensive Development Plans for Education Informatization}

\begin{tabular}{|c|c|c|c|c|}
\hline & & $\begin{array}{c}\text { ICT Promotion } \\
\text { Phase(2001 2005) }\end{array}$ & $\begin{array}{c}\text { Services } \\
\text { Sophistication } \\
\text { Phase(2006 2010) }\end{array}$ & $\begin{array}{c}\text { Smart Education } \\
\text { Phase(2011 ) }\end{array}$ \\
\hline & & Count(\%) & Count(\%) & Count(\%) \\
\hline & Instructional Systems Design & $0(0.0 \%)$ & $5(11.6 \%)$ & $0(0.0 \%)$ \\
\hline & Message Design & $0(0.0 \%)$ & $2(4.7 \%)$ & $1(11.1 \%)$ \\
\hline Design & Instructional Strategy/Method & $1(5.9 \%)$ & $2(4.7 \%)$ & $0(0.0 \%)$ \\
\hline & Learner Characteristics & $1(5.9 \%)$ & $9(20.9 \%)$ & $6(66.7 \%)$ \\
\hline Medium De & opment & $1(5.9 \%)$ & $2(4.7 \%)$ & $0(0.0 \%)$ \\
\hline & Medium Utilization & $2(11.8 \%)$ & $2(4.7 \%)$ & $0(0.0 \%)$ \\
\hline & Innovation and Distribution & $1(5.9 \%)$ & $4(9.3 \%)$ & $0(0.0 \%)$ \\
\hline & Action and System & $1(5.9 \%)$ & $4(9.3 \%)$ & $0(0.0 \%)$ \\
\hline & Policy and Regulation & $3(17.6 \%)$ & $2(4.7 \%)$ & $0(0.0 \%)$ \\
\hline
\end{tabular}




\begin{tabular}{l|l|c|c|c}
\hline \multirow{4}{*}{ Management } & Project Management & $1(5.9 \%)$ & $0(0.0 \%)$ & $0(0.0 \%)$ \\
\cline { 2 - 5 } & Resources Management & $0(0.0 \%)$ & $2(4.7 \%)$ & $0(0.0 \%)$ \\
\cline { 2 - 5 } & Transfer System Management & $0(0.0 \%)$ & $2(4.7 \%)$ & $0(0.0 \%)$ \\
\cline { 2 - 5 } & Information Management & $1(5.9 \%)$ & $1(2.3 \%)$ & $0(0.0 \%)$ \\
\hline \multirow{5}{*}{ Evaluation } & Problem Analysis & $0(0.0 \%)$ & $0(0.0 \%)$ & $0(0.0 \%)$ \\
\cline { 2 - 5 } & Criterion Referenced Assessment & $0(0.0 \%)$ & $1(2.3 \%)$ & $0(0.0 \%)$ \\
\cline { 2 - 5 } & Formative Evaluation & $0(0.0 \%)$ & $0(0.0 \%)$ & $0(0.0 \%)$ \\
\cline { 2 - 5 } & Summative Evaluation & $0(0.0 \%)$ & $0(0.0 \%)$ & $0(0.0 \%)$ \\
\hline \multirow{5}{*}{ Others } & Introduction & $3(\mathbf{1 7 . 6 \% )}$ & $0(0.0 \%)$ & $0(0.0 \%)$ \\
\cline { 2 - 5 } & Learning Environment & $0(0.0 \%)$ & $1(2.3 \%)$ & $\mathbf{2}(\mathbf{2 2 . 2} \%)$ \\
\cline { 2 - 5 } & Learning Theory & $0(0.0 \%)$ & $1(2.3 \%)$ & $0(0.0 \%)$ \\
\cline { 2 - 5 } & Exploration & $2(11.8 \%)$ & $3(7.0 \%)$ & $0(0.0 \%)$ \\
\hline
\end{tabular}

As Table 3 shows, the "ICT Promotion Phase", the second phase of the CDPEI, showed many of the papers (17.6\%) during that period focused on regulations and policies affecting the use and distribution of e-learning (application-policy and regulation), and on new approaches based on new ideas, or the introduction and explanation of technologies and future prospects (others-introduction). In the third "Services Sophistication Phase" and the newly launched "Smart Education Phase", papers (20.9\% and 66.7\% respectively) were primarily about how to discover and reflect the learners' characteristics that need to be considered in designing (design-learner characteristics).

\subsection{Trend Analysis by Research Method}

The 69 papers selected for the study have been categorized based on Driscoll's categorization and the Richey and Nelson's developmental research [36, 37]. The categorization results are complied in Table 4.

Table 4. Trend Analysis by Research Method

\begin{tabular}{|c|c|c|c|c|}
\hline & \multicolumn{3}{|c|}{ CDPEI Phases } & \multirow[b]{2}{*}{ Total } \\
\hline & $\begin{array}{c}\text { ICT Promotion } \\
\text { Phase(2001 } \\
\text { 2005) }\end{array}$ & $\begin{array}{c}\text { Services } \\
\text { Sophistication } \\
\text { Phase(2006 } \\
\text { 2010) }\end{array}$ & $\begin{array}{c}\text { Smart Education } \\
\text { PhaseM } \\
(2011 \sim)\end{array}$ & \\
\hline & Count(\%) & Count(\%) & Count(\%) & Count(\%) \\
\hline Experimental Research & $1(5.9 \%)$ & $5(11.6 \%)$ & $1(11.1 \%)$ & $7(10.1 \%)$ \\
\hline Quasi-Experimental Research & $0(0.0 \%)$ & $0(0.0 \%)$ & $0(0.0 \%)$ & $0(0.0 \%)$ \\
\hline Survey Research & $6(35.3 \%)$ & $21(48.8 \%)$ & $7(77.8 \%)$ & $34(49.3 \%)$ \\
\hline Case Study / Ethnography Research & $5(29.4 \%)$ & $4(9.3 \%)$ & $1(11.1 \%)$ & $10(14.5 \%)$ \\
\hline
\end{tabular}




\begin{tabular}{l|c|c|c|c}
\hline Developmental Research Type 1 & $0(0.0 \%)$ & $2(4.7 \%)$ & $0(0.0 \%)$ & $2(2.9 \%)$ \\
\hline Developmental Research Type 2 & $0(0.0 \%)$ & $3(7.0 \%)$ & $0(0.0 \%)$ & $3(4.3 \%)$ \\
\hline Cost Effectiveness Analysis Research & $0(0.0 \%)$ & $0(0.0 \%)$ & $0(0.0 \%)$ & $0(0.0 \%)$ \\
\hline Literature Review & $1(5.9 \%)$ & $6(14.0 \%)$ & $0(0.0 \%)$ & $7(10.1 \%)$ \\
\hline Others & $4(23.5 \%)$ & $2(4.7 \%)$ & $0(0.0 \%)$ & $6(8.7 \%)$ \\
\hline
\end{tabular}

Table 4 shows that overall the survey research, where research is done based on paper questionnaires, data investigation or phenomenon description, was predominant (49.3\%). In the ICT Promotion phase, the second phase of the CDPEI, many of the papers were found to be qualitative research (case study / ethnographic research), which try to explain reasons or processes behind an approach by way of phenomenon analysis through observation, interview or data analysis, etc. In the third Services Sophistication phase, a high percentage of papers were categorized as literature review that examines previous research or literature. Case study / literature review and experimental research accounted for a high portion of the papers in the newly launched Smart Education phase.

\subsection{Relations between Research Area and Research Method}

Cross analysis has been conducted to see if there is a statistically meaningful relation between research areas and methods. 92.9\% of the cells, however, had expected frequencies of less than 5, so Fisher's exact test was taken instead. The resulting value turned out to be 42.019 ( $\mathrm{p}=0.012<0.05)$, meaning there is a distribution difference between research areas and methods. The analysis results are shown in Table 5.

Table 5. Relations Between Research Area and Method

\begin{tabular}{|c|c|c|c|c|c|c|c|c|}
\hline Research Method & d Research Area & Design & $\begin{array}{c}\text { Medium } \\
\text { Development }\end{array}$ & Application & Management & Evaluation & Others & $\begin{array}{c}\text { Fisher's } \\
\text { exact test / } \\
\text { p }\end{array}$ \\
\hline \multirow{3}{*}{$\begin{array}{l}\text { Experimental } \\
\text { Research }\end{array}$} & Count & 4 & 1 & 1 & 1 & 0 & 0 & \multirow{10}{*}{$\begin{array}{l}42.019 \\
/ .012 *\end{array}$} \\
\hline & Expected Count & 2.7 & .3 & 1.9 & .7 & .1 & 1.2 & \\
\hline & $\begin{array}{l}\text { \% within } \\
\text { Research Area }\end{array}$ & $14.8 \%$ & $33.3 \%$ & $5.3 \%$ & $14.3 \%$ & $0.0 \%$ & $0.0 \%$ & \\
\hline \multirow{3}{*}{ Survey Research } & Count & 16 & 1 & 11 & 1 & 1 & 4 & \\
\hline & Expected Count & 13.3 & 1.5 & 9.4 & 3.4 & .5 & 5.9 & \\
\hline & $\begin{array}{l}\text { \% within } \\
\text { Research Area }\end{array}$ & $59.3 \%$ & $33.3 \%$ & $57.9 \%$ & $14.3 \%$ & $100.0 \%$ & $33.3 \%$ & \\
\hline \multirow{3}{*}{$\begin{array}{l}\text { Case Study / } \\
\text { Ethnographic } \\
\text { Research }\end{array}$} & Count & 0 & 1 & 5 & 1 & 0 & 3 & \\
\hline & Expected Count & 3.9 & .4 & 2.8 & 1.0 & .1 & 1.7 & \\
\hline & $\begin{array}{l}\text { \% within } \\
\text { Research Area }\end{array}$ & $0.0 \%$ & $33.3 \%$ & $26.3 \%$ & $14.3 \%$ & $0.0 \%$ & $25.0 \%$ & \\
\hline Developmental & Count & 1 & 0 & 0 & 1 & 0 & 0 & \\
\hline
\end{tabular}




\begin{tabular}{|c|c|c|c|c|c|c|c|}
\hline \multirow[t]{2}{*}{ Research Type 1} & Expected Count & .8 & .1 & .6 & .2 & .0 & .3 \\
\hline & $\begin{array}{l}\text { \% within } \\
\text { Research Area }\end{array}$ & $3.7 \%$ & $0.0 \%$ & $0.0 \%$ & $14.3 \%$ & $0.0 \%$ & $0.0 \%$ \\
\hline \multirow{3}{*}{$\begin{array}{l}\text { Developmental } \\
\text { Research Type } 2\end{array}$} & Count & 2 & 0 & 0 & 0 & 0 & 1 \\
\hline & Expected Count & 1.2 & .1 & .8 & .3 & .0 & .5 \\
\hline & $\begin{array}{l}\text { \% within } \\
\text { Research Area }\end{array}$ & $7.4 \%$ & $0.0 \%$ & $0.0 \%$ & $0.0 \%$ & $0.0 \%$ & $8.3 \%$ \\
\hline \multirow{3}{*}{$\begin{array}{l}\text { Literature } \\
\text { Review }\end{array}$} & Count & 3 & 0 & 2 & 2 & 0 & 0 \\
\hline & Expected Count & 2.7 & .3 & 1.9 & .7 & .1 & 1.2 \\
\hline & $\begin{array}{l}\text { \% within } \\
\text { Research Area }\end{array}$ & $11.1 \%$ & $0.0 \%$ & $10.5 \%$ & $28.6 \%$ & $0.0 \%$ & $0.0 \%$ \\
\hline \multirow{3}{*}{ Others } & Count & 1 & 0 & 0 & 1 & 0 & 4 \\
\hline & Expected Count & 2.3 & .3 & 1.7 & 6 & .1 & 1.0 \\
\hline & $\begin{array}{l}\text { \% within } \\
\text { Research Area }\end{array}$ & $3.7 \%$ & $0.0 \%$ & $0.0 \%$ & $14.3 \%$ & $0.0 \%$ & $33.3 \%$ \\
\hline \multirow{3}{*}{ Total } & Count & 27 & 3 & 19 & 7 & 1 & 12 \\
\hline & Expected Count & 27.0 & 3.0 & 19.0 & 7.0 & 1.0 & 12.0 \\
\hline & $\begin{array}{l}\text { \% within } \\
\text { Research Area }\end{array}$ & $100.0 \%$ & $100.0 \%$ & $100.0 \%$ & $100.0 \%$ & $100.0 \%$ & $100.0 \%$ \\
\hline
\end{tabular}

$* \mathrm{p}<0.05$

39 cells (92.9\%) have expected count less than 5.

\subsection{Meta-Analysis on Relations with Learning Effect}

Eight papers on e-learning and its effectiveness have been taken to extract a total of 33 effect sizes. These data have been used to calculate mean effect sizes of e-learning, as shown in Table 6.

Table 6. Mean Effect Sizes of E-Learning

\begin{tabular}{l|c|c|c|c|c|c}
\hline Effect Model & Mean ES & $-95 \%$ CI & $+95 \%$ CI & SE & Z & P \\
\hline Fixed & .182 & .132 & .232 & .026 & 7.090 & .000 \\
\hline Random &. $\mathbf{3 0 1}$ &. $\mathbf{1 3 1}$ & $\mathbf{. 4 7 1}$ & $\mathbf{. 0 8 7}$ & $\mathbf{3 . 4 6 6}$ & $\mathbf{. 0 0 1}$ \\
\hline \multicolumn{7}{l}{ Homogeneity Analysis: Q=62.908, df=7, $\mathrm{p}=.000$} \\
\hline
\end{tabular}

A homogeneity analysis on the effectiveness of e-learning showed that homogeneity assumption had not been secured $(\mathrm{Q}=62.908, \mathrm{df}=7, \mathrm{p}=.000)$. Therefore, analysis was carried out under a random effects model, and the overall mean effect size turned out to be .301 $(p=.001)$. The results indicate that the group that had used e-learning showed better performances than other groups. 
4.5.1. Changes in Effect Size Depending on Learner Background: Learners' background variables were taken into consideration to calculate effect sizes, as shown in Table 7.

Table 7. Mean Effect Sizes by Learner Background Variable

\begin{tabular}{l|c|c|c|c|c|c}
\hline Effect Model & Mean ES & $-95 \%$ CI & $+95 \%$ CI & SE & Z & P \\
\hline Fixed & .129 & .066 & .192 & .032 & 3.992 & .000 \\
\hline Random & .284 & .004 & .563 & .143 & $\mathbf{1 . 9 8 4}$ & $\mathbf{. 0 4 7}$ \\
\hline
\end{tabular}

Homogeneity Analysis: $\mathrm{Q}=38.212, \mathrm{df}=3, \mathrm{p}=.000$

A homogeneity analysis on learning effect depending on learners' background variables showed that homogeneity assumption had not been secured $(\mathrm{Q}=38.212, \mathrm{df}=3, \mathrm{p}=.000)$. Therefore, analysis was carried out under a random effects model, and the overall mean effect size turned out to be .284 ( $\mathrm{p}=.047)$.

4.5.2. Effect Size by Environmental Variable: Effect sizes have been calculated based on elearning environmental variables, as shown in Table 8.

Table 8. Mean Effect Sizes by E-Learning Environmental Variable

\begin{tabular}{l|c|c|c|c|c|c}
\hline Effect Model & Mean ES & $-95 \%$ CI & $+95 \%$ CI & SE & Z & P \\
\hline Fixed & .274 & .191 & .358 & .042 & 6.466 & .000 \\
\hline Random & .328 & .103 & .553 &. $\mathbf{1 1 5}$ & $\mathbf{2 . 8 5 2}$ & $\mathbf{. 0 0 4}$ \\
\hline
\end{tabular}

Homogeneity Analysis: Q=17.224, df=3, p=.001

A homogeneity analysis on learning effect depending on e-learning environmental variables showed that homogeneity assumption had not been secured $(\mathrm{Q}=17.224, \mathrm{df}=3$, $\mathrm{p}=.001$ ). Therefore, analysis was carried out under a random effects model, and the overall mean effect size turned out to be $.328(\mathrm{p}=.004)$.

\section{Discussion and Suggestion}

The purpose of this study was to review the learning effect of e-learning, which has been performed for last 10 years through the e-learning study trend analysis. To achieve this purpose, 350 papers published in the journal of "Korean Education Information Media" from 2002 to 2013 were chosen for the study subject, and among them, e-learning related 69 papers were selected to study the trend of e-learning. Furthermore, 16 papers of experiment study and case studies were extracted to derive the learning effect of e-learning as well as to quantify the effect. 


\subsection{E-Learning-related Study Trends}

As for e-learning study trend by time period, "ICT utilization and facilitation step (2001 to 2005)", which is the second step of the Measure for Comprehensive Education Information Advancement, has been concentrated on studies on regulations and policies regarding penetration and use of e-learning (utilization-policy and regulation), approaches to new ideas, and introduction, description and future prospect of technologies take mainly (17.6\% for each). During the "Service Advancement Step"(2006 to 2010), and "Smart Education Enforcement Step"(2011 to ), which is the third step, studies of variables of the characteristics of learners, which were required to be considered for the design, were examined and how to take them into consideration (design-learner's characteristics), were the main study areas (20.9\% and $66.7 \%$ respectively). Moreover, the analysis result of the study method trend showed that survey questionnaire to study the status or studies of examining the data on the study target to explain the phenomenon (examination study) were the two main methods (49.3\%). The test result whether significant correlation is present between the study areas and study method through the Fisher's exact test showed 42.019 ( $p=0.012<0.05$ ), meaning that there was a difference of distribution between the study areas and the study methods.

\subsection{Effectiveness of e-Learning}

First, a close look into overall effect sizes of e-learning revealed that the group benefiting from e-learning showed positive performances than others. However, when Cohen's approach is taken into consideration in interpreting effect sizes, the mean effect size of e-learning is somehow small (Mean ES=.301) [39][40].

Second, a close look into overall effect sizes according to learners' background variables resulted in a mean effect size of .284 ( $\mathrm{p}=.047)$. Even when Cohen's interpretation is applied, the effect size is still small, and the significance level is too little to be meaningful.

Third, overall effect sizes have been looked into in relation to e-learning environmental variables, resulting in a mean effect size of .328 ( $\mathrm{p}=.004)$. It is greater than the effect size in the previous case of the learners' background variables, and its significance level is also statistically more meaningful.

In closing, I should like to make suggestions for following studies based on the process and conclusions of this study. This study looked into trends in e-learning research conducted for the past ten years and examined the effectiveness of e-learning. It then seeks to set the right direction for e-learning to be headed, and also helps to reach agreement on conditions or environments that would optimize the effectiveness of e-learning. This study, however, has its limits in that the study did not cover all previous studies on e-learning, but only those on the effectiveness of e-learning. Therefore, as a way to continuously keep track of and systemically manage the effectiveness of e-learning, an ecological approach or a comprehensive analysis should follow. In addition, there is a clear need for meta-analysis on the roles and effectiveness of learning environment and learning medium.

\section{References}

[1] K. S. Jung and K. J. Kim, "Factors Influencing the Learning Effectiveness and Transfer of e-Learning in Business Organizations”, Journal of information systems, vol. 15, (2006), pp. 1-29.

[2] J. Y. Hwang and M. S. Choi, "Learning Achievement and Educational Satisfaction According to Learners` Background Variables and Learning Strategies in Online Teacher Training”, Journal of Educationa Information and Media, vol. 12, (2006), pp. 255-274.

[3] H. S. Park and C. M. Kim, "The Effects of Color Tone and Brightness on Recall and Recognition while Information Presented in E-learning Environment”, Journal of Educationa Information and Media, vol. 14, (2008), pp. 55-79. 
[4] Y. G. Baek, J. K. Kim and G. M. Kim, "The Effect of Fidelity Levels in the Computer Simulation on the Academic Achievement by Learner`s Cognitive Style”, Journal of Educationa Information and Media, vol. 6, (2000), pp. 45-72.

[5] S. H. Wang, B. G. Kim and Y. G. Baek, "The effect of graphic material type and children's cognitive style on mathematical space perception in web environment”, Journal of Educational Research, vol. 41, (2003), pp. 457-489.

[6] H. Y. Jeong and S. H. Kim, "An Empirical Study on Critical Success Factors in Implementing the WebBased Distance Learning System”, Journal of information systems, vol. 11, (2002), pp. 51-74.

[7] M. H. Kang, "A Case Study on Factors Affecting Instructional Effectiveness in a Web-based Learning Environment in University”, Korean Journal of Higher Education, vol. 13, (2002), pp. 1-27.

[8] H. J. Kwon, "The analysis of the relation among learner's learning style, self-directed learning attitudes, and academin achievement in the virtual class”, Master, Graduate School of Chung-Ang University, Seoul, (2001).

[9] W. S. Kang, “A Study on Factor of Academic Acheivement in the Multimedia Assisted Social Studies Education: Focused on Learner's Factor”, The Journal of Yeolin Education, vol. 11, (2003), pp. 175-194.

[10] R. M. Ryan and J. P. Connell, "Perceived locus of causality and internalization: Examining reasons for acting in two domains”, Journal of personality and social psychology, vol. 57, (1989), pp. 749-761.

[11] M. Csikszentmihalyi, K. Rathunde and S. Whalen, "Talented teenagers: The roots of success and failure”, Cambridge University Press, (1996).

[12] M. S. Fortier, R. J. Vallerand and F. Guay, "Academic motivation and school performance: Toward a structural model”, Contemporary educational psychology, vol. 20, (1995), pp. 257-274.

[13] F. Guay and R. J. Vallerand, "Social context, student's motivation, and academic achievement: Toward a process model”, Social Psychology of Education, vol. 1, (1996), pp. 211-233.

[14] R. M. Ryan and E. L. Deci, "Self-determination theory and the facilitation of intrinsic motivation, social development, and well-being”, American psychologist, vol. 55, (2000), pp. 68-78.

[15] H. J. Go and Y. J. Kim, "A Study on the types of self-determination motivation and the correlation with the academic achievements for chinese speaking korean learners”, J ournal of Korean Language Education, vol. 22, (2011), pp. 1-26.

[16] J. Y. Kim, “Teacher' conditional regard, autonomy support, and tapes of students' motivation as predictors of students' academic engagement and Achievement”, Master, Ewha Womans University, Seoul, (2010).

[17] S. G. Lee, "Individual and environmental factors in growth of academic achievement of elementary school students”, Master, Bukyung University, (2010).

[18] J. H. Lee, "Analysis of the structural relationships among self-determination motivation to learn, metacognition, self-directed learning ability, learning flow, and school achievement”, Journal of Educational Research, vol. 48, (2010), pp. 67-92.

[19] H. Ik Jo and H. Y. Kwon, "A Study on the relationship between Self-determinative motivation and Academic achievement”, Korean journal of youth studies, vol. 17, (2010), pp. 47-68.

[20] H. I. Jo and N. Y. Lee, "A study on the relationship between academic achievement and ego-resiliency: Focusing on mediating effects of self-determination motivation”, Korean journal of youth studies, vol. 17, (2010), pp. 1-20.

[21] H. J. Ju, "Analysis of the causal relationships among self-determination motivation, self-directed learning ability, academic self-efficacy and academic achievement of elementary School students”, Journal of Association for Learner-centered Curriculum and Instructional Research, vol. 11, (2011), pp. 237-259.

[22] R. A. Noe and N. Schmitt, "The influence of trainee attitudes on training effectiveness: Test of a model”, Personnel psychology, vol. 39, (1986), pp. 497-523.

[23] T. T. Baldwin and J. K. Ford, “Transfer of training: A review and directions for future research”, Personnel psychology, vol. 41, (1988), pp. 63-105.

[24] J. B. Tracey, T. R. Hinkin, S. Tannenbaum and J. E. Mathieu, "The influence of individual characteristics and the work environment on varying levels of training outcomes”, Human Resource Development Quarterly, vol. 12, (2001), pp. 5-23.

[25] H. G. Kim, S. H. Gwak and H. J. Seo, “An Empirical Study on Factors Influencing the Learning Effects of E-Learning”, Proceedings, (2004), pp. 36-44.

[26] J. H. Ryu, M. J. Kim and G. J. Ko, "Key Factors for Determining Learners` Satisfaction in Corporate ELearning”, Journal of Educationa Information and Media, vol. 11, (2005), pp. 191-220.

[27] H. J. Lee, Y. I. Hong and J. Y. Son, "Effects of Online Feedback Types among Students on Learning Outcome in a Blended e-Learning Environment”, Journal of Educationa Information and Media, vol. 13, (2007), pp. 131-157.

[28] G. S. Kim, Y. C. Han and S. H. Lee, "Factors Influencing the Effectiveness of Web-Based Distance Learning”, Korean Association Of Industrial Business Administrarion, vol. 18, (2003), pp. 195-218. 
[29] R. L. Daft and R. H. Lengel, "Organizational information requirements, media richness and structural design”, Management science, vol. 32, (1986), pp. 554-571.

[30] J. Webster and P. Hackley, "Teaching effectiveness in technology-mediated distance learning”, Academy of management journal, (1997), pp. 1282-1309.

[31] M. Freeman, "Flexibility in access, interaction and assessment: The case for web-based teaching programs", Australian Journal of Educational Technology, vol. 13, (1997), pp. 23-39.

[32] Y.-S. Wang, “Assessment of learner satisfaction with asynchronous electronic learning systems", Information \& Management, vol. 41, (2003), pp. 75-86.

[33] G. V. Glass, "Primary, secondary, and meta-analysis of research”, Educational researcher, vol. 5, (1976), pp. 3-8.

[34] H. M. Jeong and Y. C. Yang, “Journal of Educational Technology”, 20 years: Analysis on Research Domains, Research Methods, and Learning Theories, Journal of Educational Technology, vol. 21, (2005), pp. 167-194.

[35] B. Seels and R. Richey, "Instructional technology: The definition and domains of the field", Association for Educational Communications and Technology Washington, DC, (1994).

[36] M. P. Driscoll, "Paradigms for research in instructional systems”, G.J. Anglin (Ed.) Instructional technology: past, present, and future, Engle- wood, CO, Libraries Unlimited, (1995), pp. 332-329.

[37] R.C. Richey and W. A. Nelson, “Development Research”, D. Jonassen (Ed.) Handbook of Research for Educational Communications and Technology, Macmillan, New York, (1996), pp. 1213-1245.

[38] M. W. Lipsey and D. B. Wilson, "Practical meta-analysis”, SAGE Publications, Incorporated, (2001).

[39] J. Cohen, "Statistical power analysis for the behavioral sciences”, Academic Press, (1977).

[40] J. Cohen, "Statistical Power Analysis for the Behavioral Sciencies", Lawrence Erlbaum Associates, Incorporated, (1988).

\section{Authors}

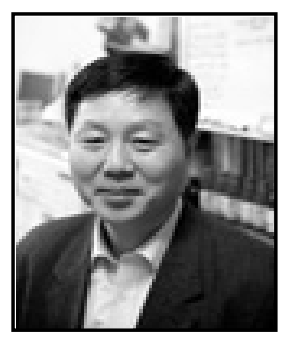

Jeong-Kyoum Kim, he received B.A., M.A., and Ed. D degrees in Education from Chungnam National University, Korea in 1988, 1990, and 1997 respectively. He is a professor at Chungnam National University, Department of Education.

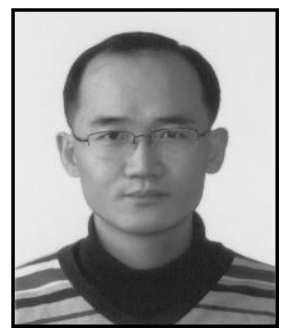

Deuk-Joon Kim, he received B.S. degrees in Electronic Engineering from Chungnam National University, M.A. degrees in Educational Technology from Korea National University of Education, ABD degree in Educational Technology from Chungnam National University, Korea in 2000, 2006, and 2009 respectively. He is a senior researcher at Daejeon University, Center for Teaching and Learning. 
International Journal of Smart Home Vol.7, No.6 (2013) 